\title{
Transparent nanostructured cellulose acetate films based on the self assembly of PEO-b-PPO-b-PEO block copolymer
}

\author{
Junkal Gutierrez $^{\mathrm{a}, \mathrm{b}, *}$, Sheyla Carrasco-Hernandez ${ }^{\mathrm{a}}$, Hernane S. Barud ${ }^{\mathrm{c}, \mathrm{d}}$, \\ Rafael L. Oliveira ${ }^{\mathrm{c}}$, Renata A. Carvalho ${ }^{\mathrm{d}}$, André C. Amaral ${ }^{\mathrm{d}}$, Agnieszka Tercjak ${ }^{\mathrm{a}, *}$ \\ a 'Materials + Technologies' Group (GMT), Department of Chemical and Environmental Engineering, Faculty of Engineering, Gipuzkoa, University of the \\ Basque Country (UPV/EHU), Plaza Europa 1, 20018 Donostia-San Sebastian, Spain \\ ${ }^{\mathrm{b}}$ Faculty of Engineering Vitoria-Gasteiz, University of the Basque Country (UPV/EHU), C/Nieves Cano, 1201006 Vitoria-Gasteiz, Spain \\ c Laboratory of Photonic Materials, Institute of Chemistry, Sao Paulo State University (UNESP), Araraquara, 14800-901 Sao Paolo, Brazil \\ ${ }^{\mathrm{d}}$ Medicinal Chemistry and Regenerative Medicine (QUIMMERA), University Center of Araraquara (UNIARA), Araraquara, 14801-340 Sao Paolo, Brazil
}

\section{A R T I C L E I N F O}

\section{Article history:}

Received 9 November 2016

Received in revised form 20 January 2017

Accepted 18 February 2017

Available online 21 February 2017

\section{Keywords:}

Cellulose acetate

Block copolymer

AFM

Composite films

Poly(ethylene oxide-b-propylene

oxide-b-ethylene oxide)

Self-assembly

\begin{abstract}
A B S T R A C T
In this study fabrication and characterization of transparent nanostructured composite films based on cellulose triacetate (CTA) and poly(ethylene oxide)-b-poly(propylene oxide)-b-poly(ethylene oxide) (EPE) triblock copolymer were presented. The effect of the addition of EPE triblock copolymer on the thermal stability, morphology, and mechanical properties of cellulose triacetate films was investigated. The triblock EPE was chosen since PEO blocks interact favorably with CTA, whereas, PPO blocks remain immiscible which provokes a microphase separation. This allows to obtain EPE/CTA composite films with ordered microphase-separated structures where PPO spherical microdomains are well-dispersed in PEO/CTA matrix by simple solvent-evaporation process. During this process, PEO block chains selectively interact with CTA by strong interpolymer hydrogen-bonding while PPO block microseparated. The addition even $40 \mathrm{wt} \%$ of EPE leads to nanostructured EPE/CTA composite. The cytotoxicity assay of CTA and EPE/CTA composite films confirm non-toxic character of designed transparent nanostructured composites based on sustainable matrices.
\end{abstract}

(c) 2017 Elsevier Ltd. All rights reserved.

\section{Introduction}

In the last years cellulose derived materials have attracted great attention due to the emerging renewable polymer industry. Cellulose is presented as a promising alternative substitute for polymers derived from petroleum sources. The most commonly used cellulose derivatives are cellulose esters, cellulose nitrate and acetate, carboxymethylcellulose, cellulose ethers, methyl and ethyl cellulose (Onofrei et al., 2012; Paunonen, 2013).

Nowadays, several research groups are working on the development of polymer nanocomposites based on matrices from renewable resources (Belgacem \& Gandini, 2008; Siqueira, Bras, \& Dufresne, 2010) with the aim to reach advanced materials economically viable, environmentally friendly and with enhanced

\footnotetext{
* Corresponding authors at: 'Materials + Technologies' Group (GMT), Department of Chemical and Environmental Engineering, Faculty of Engineering, Gipuzkoa University of the Basque Country (UPV/EHU), Plaza Europa 1, 20018 Donostia-San Sebastian, Spain.

E-mail addresses: juncal.gutierrez@ehu.eus (J. Gutierrez), agnieszka.tercjaks@ehu.eus (A. Tercjak).
}

properties for specific applications. In particular, cellulose acetate (CA) has been extensively used as matrix to design this kind of novel nanocomposites taking into account its cost effectiveness, relatively easier manufacturing, non-toxicity, good biocompatibility and mechanical rigidity (Braganca \& Rosa, 2003; Fidale et al., 2010; Fischer et al., 2008). Accordingly, numerous papers related to the improvement of CA properties by combining it with different polymers such as poly(ethylene oxide) (Kamal, Abd-Elrahim, \& Lotfy, 2014), poly( $\varepsilon$-caprolactone) (Ali, 2014), poly(isophthalamide) (Jayalakshmi et al., 2014), polysiloxane (Brandao, Yoshida, Felisberti, \& Gonçalves, 2013) and additives such as liquid crystals (Martínez-Felipe, Ballester-Sarrias, Imrie, \& RibesGreus, 2010; Shuiping, Lianjiang, Weili, Xiaoqiang, \& Yanmo, 2010), clay (Park, Misra, Drzal, \& Mohanty, 2004) and graphene (de Moraes et al., 2015; Gopiraman, Fujimori, Zeeshan, Kim, \& Kim, 2013; Jeon, An, \& Jeong, 2012) have been published. Some researchers have also used starch nanocrystals acetate (Huang, Wu, Yu, \& Lu, 2015) and hydroxypropyl cellulose (Onofrei et al., 2014). Here it should be mentioned that based on our knowledge poly(propylene oxide) PPO was not used to develop polymer blends with CA. How- 
ever, preparation and characterization of nanostructured polymer blends based on this kind of renewable polymers is still a challenge.

In this context, block copolymers (BCP) were presented as ideal tools for the fabrication of nanostructured polymeric materials (Hamley, 2003; Singh, Thakre, More, Sharma, \& Agrawal, 2015). $\mathrm{BCP}$ can act as nanostructuring agent of polymer blends. Thus, BCP consist of two or more chemically different macromolecules that are connected covalently. This kind of macromolecules can selfassemble to produce well-defined structures (spherical, cylindrical, lamellar, gyroidal, among others) at the nanoscale (Ji, Wan, Liu, \& Nealey, 2016; Smart et al., 2008). The adequate choice of the block copolymer is the key issue to get a nanostructured polymeric blend. To reach a nanostructure is necessary at least one block inmiscible with CA matrix. To the best of our knowledge, there is no previous report in the literature dealing with the addition of block copolymers to the CA matrix to fabricate nanostructured transparent films.

The aim of this work was the development of transparent nanostructured films, consequently as well as the block copolymer choice, made a good election of cellulose acetate type was also crucial to achieve this goal. As it is well known, CA properties are highly dependent on degree of substitution (DS). For this work, cellulose acetate with DS of 2.9, named cellulose triacetate (CTA), was wellestablished as more suitable cellulose acetate to develop materials by film casting technique (Fischer et al., 2008).

In present work, transparent nanostructured cellulose triacetate films were prepared based on the self-assembly of poly(ethylene oxide-b-propylene oxide-b-ethylene oxide) (EPE) triblock copolymer and following a feasible pathway. The optical, thermal, morphological and mechanical properties of EPE/CTA composites were analyzed by UV-vis spectroscopy, thermogravimetrical analysis (TGA), differential scanning calorimetry (DSC), atomic force microscopy (AFM) and tensile test. In addition, contact angle and water vapor permeability were also investigated. From the point of view of potential applications in the field of tissue engineering, cytotoxicity assays were performed.

\section{Hypothesis}

CTA modified with a block copolymer with one miscible and one immiscible block with CTA matrix allows to develop nanostructured materials with tunable morphologies. Due to strong interactions between miscible block of the block copolymer and CTA matrix an enhancement of final properties are expected.

\section{Material and methods}

\subsection{Materials}

Cellulose triacetate (CTA, Mn $50000 \mathrm{~g} \mathrm{~mol}^{-1}$ ) with a degree of substitution (DS) equal to 2.92 (calculated from ${ }^{13} \mathrm{C}$ NMR provided in the section of Supporting information (Fig. S1)) and poly(ethylene oxide-b-propylene oxide-b-ethylene oxide) (EPE) triblock copolymer $\left(\mathrm{M}_{\mathrm{n}} 5800 \mathrm{~g} \mathrm{~mol}^{-1}\right.$ and $30 \mathrm{wt} \%$ of poly(ethylene oxide)) were purchased from Sigma Aldrich. Acetone was supplied by Panreac. All chemicals were used as without further purification.

\subsection{Film preparation}

CTA and EPE (in different weight ratios) were separately dissolved in acetone ( $5 \mathrm{wt} \%$ ). The mixture was left under stirring for $24 \mathrm{~h}$ at room temperature. After that, solutions were casted into petri-dishes ( $9 \mathrm{~cm}$ in diameter), followed by solvent evaporation at room temperature to obtain EPE/CTA transparent composite films. Two different composites were prepared, 10EPE/90CTA and 40EPE/60CA.

\subsection{Film thickness}

Film thickness was measured to the nearest $0.001 \mathrm{~mm}$ with a hand-held digimatic micrometer (QuantuMike Mitutoyo). The values obtained for each sample at five different locations were averaged. In this case, the thickness of all fabricated films was almost the same, $85 \pm 5 \mu \mathrm{m}$.

\subsection{Methods}

The optical properties of CTA and EPE/CTA composite films were analyzed by means of UV-3600, Shimadzu UV-VIS-NIR spectrophotometer in the wavelength range of $200-800 \mathrm{~nm}$.

Thermal properties were investigated by thermogravimetric analysis (TGA) and differential scanning calorimetry (DSC). The thermogravimetric analysis was performed with a TGA/SDTA-851e equipment under air atmosphere at a heating rate of $10^{\circ} \mathrm{C} \mathrm{min}-1$ from room temperature to $700^{\circ} \mathrm{C}$.

Differential scanning calorimetry (DSC) measurements were performed on a Mettler Toledo DSC-822 differential scanning calorimeter equipped with a sample robot TSO 801 RO. Three consecutive scans were performed, first heating from 25 to $250^{\circ} \mathrm{C}$ followed by cooling from 250 to $25^{\circ} \mathrm{C}$ and final heating from 25 to $250^{\circ} \mathrm{C}$. All scans were carried out at a heating rate of $20^{\circ} \mathrm{C} \mathrm{min}-1$ in sealed aluminum pans containing a sample weight of $\sim 7 \mathrm{mg}$. The middle point of the slope change of the heat capacity plot was taken as the glass transition temperature $\left(\mathrm{T}_{\mathrm{g}}\right)$. The melting temperature $\left(T_{m}\right)$ was defined as the maximum of the melting peak. $T_{g}$ and $T_{m}$ values in plotted thermograms correspond to the second heating scan.

Morphological characterization was performed using atomic force microscopy (AFM). AFM phase images were obtained by operating in tapping mode with a scanning probe microscope, Dimension Icon from Bruker. In this investigation, etched single beam cantilevers (110-140 $\mu \mathrm{m}$ length) composed by silicon nitride probes having a tip with nominal radius of $10 \mathrm{~nm}$ were used. Scan rates were ranged from 0.7 to $1.2 \mathrm{~Hz} \mathrm{~s}^{-1}$. Measurements were performed with 512 scan lines and target amplitude around $0.9 \mathrm{~V}$. Different regions of the samples were scanned to ensure that the morphology of the investigated materials is the representative one.

The tensile strength and elongation at break of the films were measured on a electromechanical testing system (MTS Insight 10) with load cell of $250 \mathrm{~N}$. Test were performed at room temperature and all samples were conditioned for $48 \mathrm{~h}$ under vacuum prior to testing. The specimens were in a rectangular shape with a dimension of $40 \mathrm{~mm} \times 5 \mathrm{~mm}$. The length between two grips was set as $20 \mathrm{~mm}$ and samples were tested with strain rate of $1 \mathrm{~mm} / \mathrm{min}$. Elongation at break and tensile strength were calculated as an averaged out from five test specimen data.

Contact angle studies were carried out using a Data Physics OCA Series instrument. Static sessile drop experiments were made using water as the wetting liquid and a drop volume of $5 \mu \mathrm{L}$. All experiments were performed at room temperature and as an average of results from five test specimens.

Water vapor permeability was measured by Payne's cup technique using $\mathrm{P}_{2} \mathrm{O}_{5}$ as a drying agent. To perform the analysis, permeation to water vapor was carried as described in the work of Morelli and Ruvolo Filho (2010) in which one can analyze the ability of each sample to permeate by its loss of mass, which was directly proportional to the loss of water flowing through the film in this case. Controlled environmental chamber conditions were a constant temperature of $25 \pm 1^{\circ} \mathrm{C}$, pressure of vaporization of water of $23.76 \mathrm{mmHg}$ and $0 \%$ relative humidity. Specimens were 
prepared cutting films into a circle with a test area of $7.2 \mathrm{~cm}^{2}$. Three specimens of each investigated sample were analyzed.

Water vapor transmission rate (WVTR) was calculated as:

$\mathrm{WVTR}=\frac{\mathrm{G}}{\mathrm{t} \cdot \mathrm{A}}$

where $G$ is the change in weight $(\mathrm{g})$, $t$ is the time $(\mathrm{h})$, and $A$ is the area of the specimen $\left(\mathrm{m}^{2}\right)$.

Water Vapor Permeability (WVP) was calculated following Eq. (2):

$\mathrm{WVP}=\frac{\mathrm{WVTR} \cdot \mathrm{T}}{\Delta \mathrm{P}}$

where $\mathrm{T}$ is the thickness of the specimen $(\mathrm{mm})$ and $\Delta \mathrm{P}$ is the partial pressure difference of the water vapor across the specimen.

To perform the cytotoxicity measurements, CTA and investigated EPE/CTA composite films were weighed, minced and immersed in cell culture Dulbeccos Modified Eagle's Medium (DMEM-Vitrocell) supplemented with $10 \%$ fetal bovine serum (FBSVitrocell) and antibiotics (Penicillin and Streptomycin - Vitrocell) for $120 \mathrm{~h}$. After this step, all samples were removed and the resultant medium was placed in a cell culture plate wells (96 wells) containing human osteoblasts (cell line MG63) in cell density $15 \times 10^{3}$ cells/well. The plates were kept in cell culture incubator (Panasonic- $\mathrm{CO}_{2}$ incubator $\mathrm{MOC}-19 \mathrm{AIC}-\mathrm{UV}$ ) at $37^{\circ} \mathrm{C}$ with a humidified atmosphere containing $5 \% \mathrm{CO}_{2}$ and $95 \%$ air atmosphere during $48 \mathrm{~h}$. After that period, cell viability was determined by a colorimetric method MTT (tetrazolium 3-(4,5-dimethylthiazol-2yl)-2,5-diphenyltetrazolium bromide). Thus, culture medium was removed from the wells, and they were washed with phosphate buffered saline (1X PBS). Aliquots of $100 \mathrm{uL}$ of MTT (SIGMA 2128) were added to each well and cells were kept in culture conditions for $4 \mathrm{~h}$. After this period, $200 \mathrm{uL}$ of isopropyl alcohol was added and the content of the wells was mechanically homogenized until complete solubilization of the formazan. The optical density values (OD) were obtained using a spectrophotometer (Polaris-CELER) at $570 \mathrm{~nm}$. Cell viability (\%) was calculated relative to CTA membranes and subjected to variance analysis (one-way ANOVA), with 5\% level of significance.

\section{Results and discussion}

Fig. 1 shows digital images of the appearance of CTA and prepared EPE/CTA composite films with thickness $\sim 85 \mu \mathrm{m}$.

Here, it should be noted that EPE block copolymer was not able to form a continuous thick film by itself. Additionally, inset images show films bent with tweezers confirming that composite films were flexible. In Fig. 1 transmittance data are also shown, indicating that the addition of EPE block copolymer did not impair the transparency of CTA. Both the composite with low EPE content, 10EPE/90CTA, and the composite with high EPE content, 40EPE/60CTA, have same transmittance as CTA, 91.5\%. Thus, investigated EPE/CTA composites demonstrated high light transmittance. This indicate that designed EPE/CTA composites did not present separated domains bigger than the wavelength of light leading to nanostructured materials as prove below by AFM technique. Moreover, the high transparency of designed materials made them attractive form the point of view of future applications.

Dynamic thermogravimetric curves of CTA and CTA based composites containing different EPE block copolymer ratios are presented in Fig. 2a and b.

As shown in Fig. 2, CTA and both EPE/CTA composites presented at low temperatures slight weight loss corresponds to $1 \mathrm{wt} \%$ which can be attributed to volatile matter and the evaporation of residual absorbed water came from film preparation protocol. Temperatures of this weight loss are collected in Table 1.
In the case of CA, two steps of weight loss were observed according to the thermal degradation of the cellulose based materials (Jayalakshmi et al., 2014; Jeon, An, \& Jeong, 2012; Kamal, AbdElrahim, \& Lotfy, 2014). The first weight loss starts at $280-380^{\circ} \mathrm{C}$, which represents the main thermal degradation of the CTA chains. The second weight loss step starts at $\sim 385^{\circ} \mathrm{C}$ and was attributed to the complete thermal degradation of the degraded products. On the contrary, the TGA curve corresponding to neat EPE block copolymer showed only one step weight loss which starts at $180^{\circ} \mathrm{C}$. For both samples, CTA and EPE above 500 and $400^{\circ} \mathrm{C}$, respectively, no residue or char was visible.

The thermal degradation of EPE/CTA composites reveals a threestage degradation process. Fabricated composites merge two-step degradation process of CTA and degradation step at $180^{\circ} \mathrm{C}$ of EPE block copolymer. For 10EPE/90CTA composite it was observed that for $10 \%$ weight loss the temperature decreases $26^{\circ} \mathrm{C}$ if compare to CTA. On the contrary, for $50 \%$ weight loss the thermal stability is not changed to great extent due to the low amount of EPE added. 40EPE/60CTA composite rendered the decomposition properties with combining the characteristics of CTA and EPE as evaluated from the thermal degradation temperatures at $10 \%$ and $50 \%$ weight losses $\left(\mathrm{T}_{10 \%}\right.$ and $\mathrm{T}_{50 \%}$ ) (Table 1 ).

$\mathrm{T}_{\mathrm{g}}$ values of PEO block of the EPE block copolymer are shown in Table 1 and corresponding DSC thermograms are provided in the section of Supporting information (Fig. S2). EPE block copolymer presented a $\mathrm{T}_{\mathrm{g}}$ of $-63^{\circ} \mathrm{C}$ and in the case of 40EPE/CTA composite the $\mathrm{T}_{\mathrm{g}}$ corresponding to PEO block increased $30^{\circ} \mathrm{C}$. This phenomenon can be related with the partial miscibility between CTA and PEO block of EPE block copolymer.

DSC thermograms from 40 to $100^{\circ} \mathrm{C}$ of CTA, EPE and their EPE/CTA composites are shown in Fig. $2 c$ and corresponding $T_{m}$ values are collected in Table 1 . EPE block copolymer exhibits a $\mathrm{T}_{\mathrm{m}}$ at $56^{\circ} \mathrm{C}$ that corresponds to melting temperature of PEO block of the EPE block copolymer. As is shown in Fig. 2c, in the case of EPE/CTA composites, the melting temperature related to the PEO block decreased with the increasing of CTA content being 55 and 54 for 40EPE/60CTA and 10EPE/90CTA composites, respectively. Simultaneously, corresponding melting enthalpy of EPE/CTA composites, measured by DSC, was lower than theoretical one. This is common behavior for polymer blends with partial miscibility (Guo, Thomann, \& Gronski, 2003) and proved that the CTA hindered crystallization of PEO block of the EPE block copolymer as a consequence of the formation of intermolecular hydrogen bonds between the ether oxygen of PEO and the hydroxyl groups of CTA (Builes, Hernández-Ortiz, Corcuera, Mondragon, \& Tercjak, 2014).

Thermograms at higher temperatures, from 150 to $240^{\circ} \mathrm{C}$, are shown in Fig. 2d. For EPE block copolymer, in this temperature interval, no temperature transition was observed. On the contrary, CTA exhibits a glass transition temperature $\left(T_{g}\right)$ at $193^{\circ} \mathrm{C}$, which is in agreement with the value previously reported in the literature (Braganca \& Rosa 2003; Fidale et al., 2010). As can be seen in Table 1, the $T_{g}$ of CTA rich phase remained almost unaltered with the incorporation of 10 and $40 \mathrm{wt} \%$ of EPE block copolymer. On the other hand, under this measurements condition, the melting transition $\left(T_{m}\right)$ of CTA was slightly detected at $227^{\circ} \mathrm{C}$. The $T_{m}$ of the CTA rich phase in the EPE/CTA composites exhibited same $\mathrm{T}_{\mathrm{m}}$ value if compared with the neat CTA.

All investigated EPE/CTA composites exhibited the same $T_{m}$ value. Thus, once again melting temperature remained unaffected by the addition of EPE block copolymer (Table 1).

Morphology of investigated EPE/CTA composites was analyzed by AFM technique. Prior to AFM analysis, here, it should be pointed out, that as has been mentioned above both EPE/CTA composites were optically transparent indicating that separated domains were smaller than the wavelength of light as mentioned in UV-vis measurement discussion. As previously explained, PEO block of the EPE 

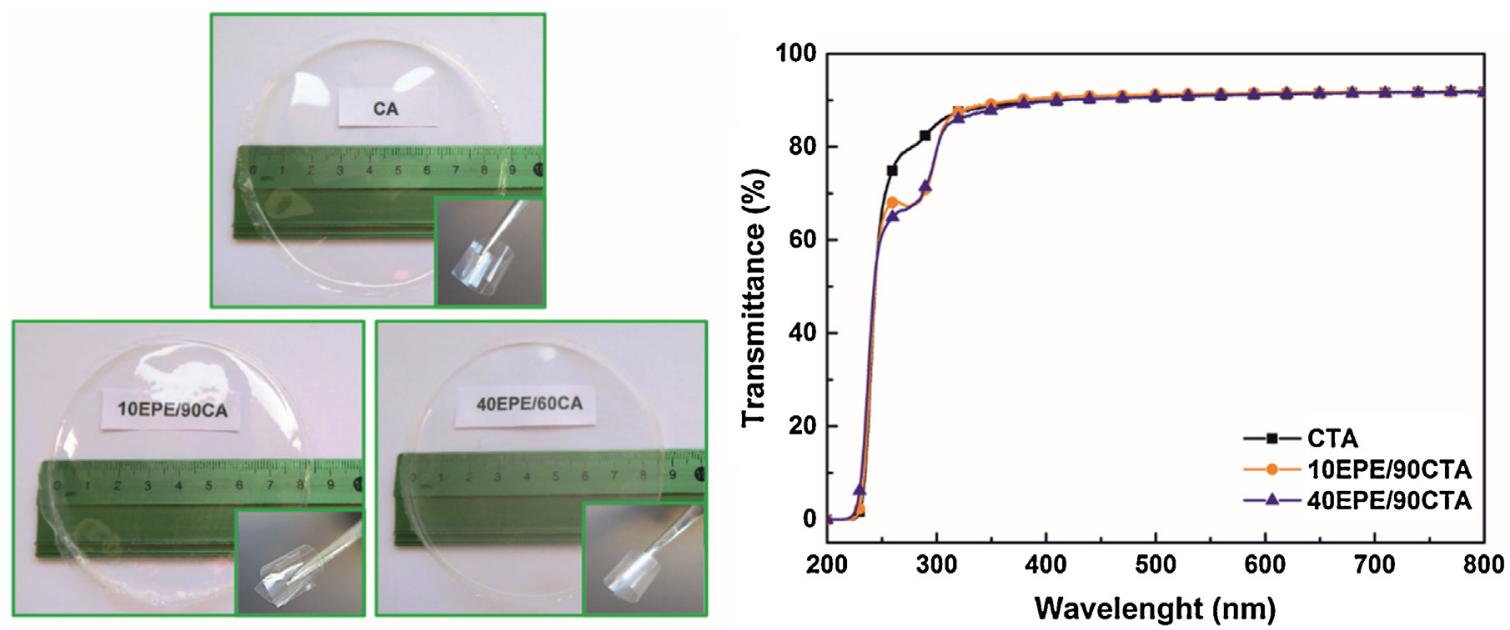

Fig. 1. Digital images and UV-vis transmittance spectra of CTA and investigated EPE/CTA composites.
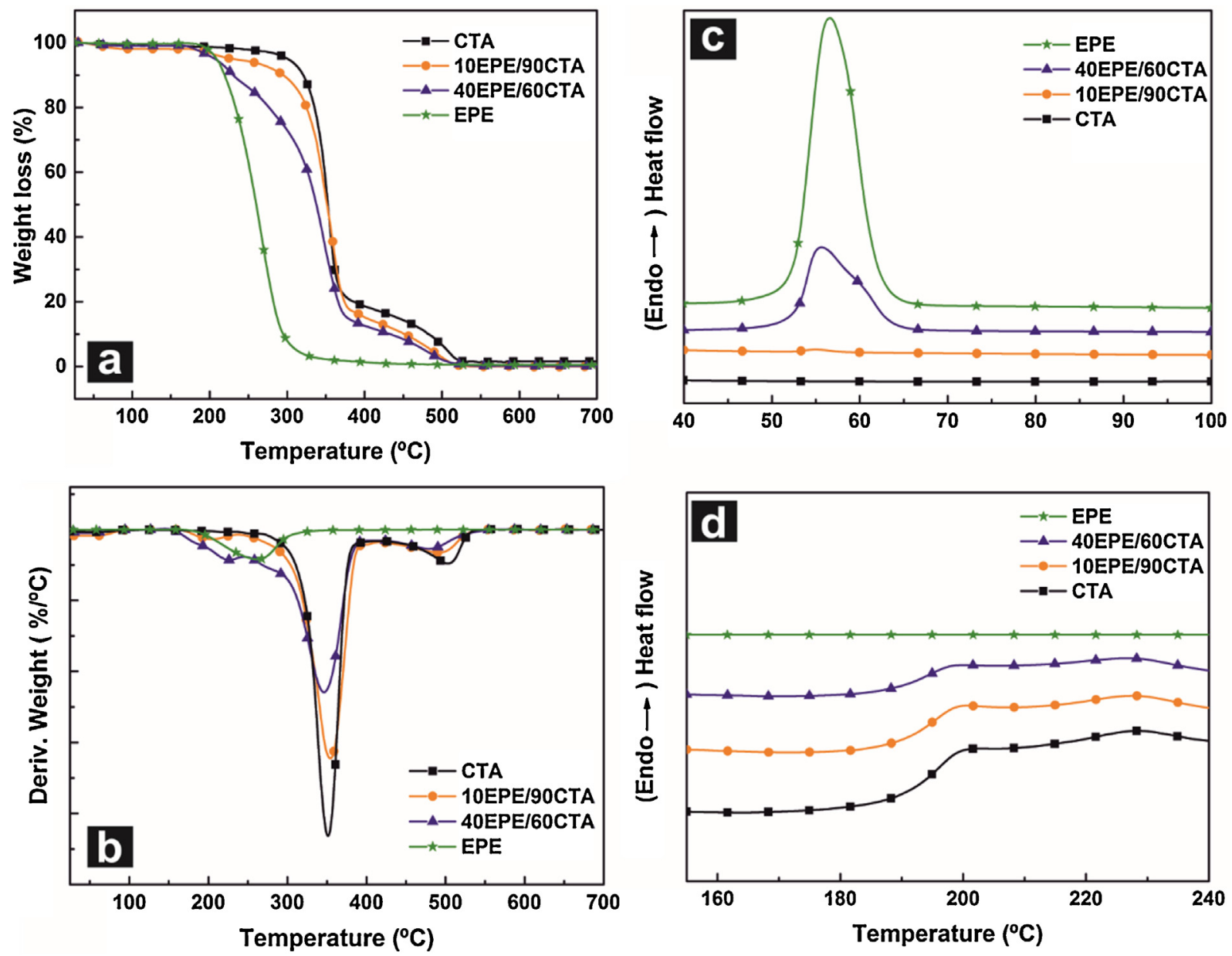

Fig. 2. a) TGA and b) DTG curves and DSC thermograms c) from 40 to $100^{\circ} \mathrm{C}$ and d) from 150 to $240{ }^{\circ} \mathrm{C}$ of $\mathrm{CTA}$, EPE and investigated EPE/CTA composites.

Table 1

Thermal degradation temperatures for $1 \%, 10 \%$ and $50 \%$ weight losses $\left(\mathrm{T}_{1 \%}, \mathrm{~T}_{10 \%}\right.$ and $\mathrm{T}_{50 \%}$ ) and thermal properties of CTA, EPE and investigated EPE/CTA composites.

\begin{tabular}{|c|c|c|c|c|c|c|c|}
\hline Samples & $\mathrm{T}_{1 \%}\left({ }^{\circ} \mathrm{C}\right)$ & $\mathrm{T}_{10 \%}\left({ }^{\circ} \mathrm{C}\right)$ & $\mathrm{T}_{50 \%}\left({ }^{\circ} \mathrm{C}\right)$ & $\mathrm{T}_{\mathrm{gEPE}}\left({ }^{\circ} \mathrm{C}\right)$ & $\mathrm{T}_{\mathrm{mEPE}}\left({ }^{\circ} \mathrm{C}\right)$ & $\mathrm{T}_{\mathrm{gCTA}}\left({ }^{\circ} \mathrm{C}\right)$ & $\mathrm{T}_{\text {mCTA }}\left({ }^{\circ} \mathrm{C}\right)$ \\
\hline CTA & 100 & 320 & 352 & - & - & 196 & 227 \\
\hline 10ЕРЕ/90СТА & 59 & 294 & 352 & - & 54 & 195 & 227 \\
\hline 40ЕРE/60СТА & 85 & 230 & 336 & -33 & 55 & 194 & 227 \\
\hline EPE & 190 & 219 & 260 & -63 & 56 & - & - \\
\hline
\end{tabular}




\section{EPE/90CTA}

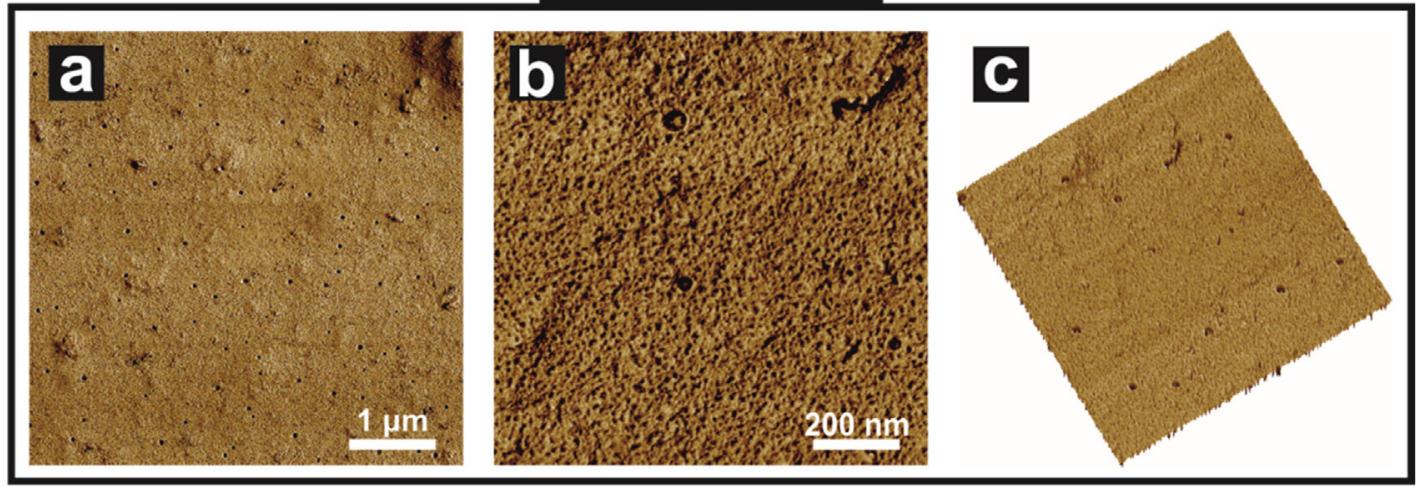

40EPE/60CTA

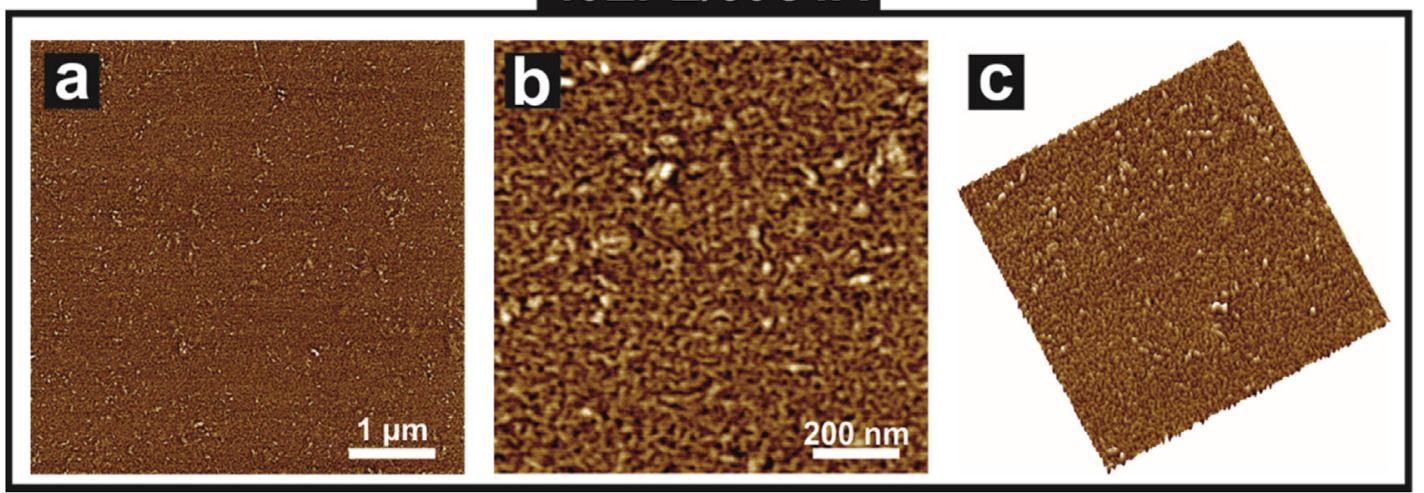

Fig. 3. AFM phase images of investigated EPE/CTA composites a) $5 \mu \mathrm{m} \times 5 \mu \mathrm{m}$, b) $1 \mu \mathrm{m} \times 1 \mu \mathrm{m}$ and c) $2 \mu \mathrm{m} \times 2 \mu \mathrm{m} 3 \mathrm{D}$ image.

block copolymer is partially miscible with the CTA matrix, consequently microphase separation of the PPO block domains could take place.

Fig. 3 shows AFM phase images at different magnifications for 10EPE/90CTA and 40EPE/60CTA composites. For comparison, AFM phase images of CTA were also provided in the section of Supporting information (Fig. S3).

The light continuous areas in the AFM-phase images correspond to CTA matrix mixed with the PEO block, whereas the dark areas correspond to PPO block domains of the EPE block copolymer. For 10EPE/90CTA composite, Fig. 3a, slight contrast can be observed, where no clear phase separation occurred. However, high magnification image, Fig. 3b, reveals a spherical morphology with a size between 10 and $15 \mathrm{~nm}$ corresponding to the PPO block rich phase microphase separated in CTA rich matrix. Additionally, 3D image clearly shows a smooth surface with some nanodefects caused by solvent evaporation.

When the content of EPE block copolymer increased, the spherical morphology changed to worm-like structure. Additionally, some brightest domains attributed to hardest PEO block nanocrystals were observed. Detected brightest nanocrystals are located inside CTA rich matrix. In this case, the high amount of EPE block copolymer provoked the crystallization of some domains of PEO block embedded in CTA rich matrix as confirmed by DSC measurements. These PEO nanocrystals appeared well-dispersed and were mainly homogenous in size $\sim 20 \mathrm{~nm}$.

The mechanical properties of CTA and EPE/CTA composite films are shown in Table 2 and in order to clarify the influence of the addition of EPE block copolymer on the stress-strain curve of CTA film these stress-strain curves were also provided as Supporting information (Fig. S4). In this case, a large drop in strength and a large increase in ductility can be clearly observed for the composite with high amount of EPE block copolymer.

Moreover, in Table 2, the results revealed that for 10EPE/90CTA composite mechanical properties remain almost constant. On the contrary, the addition of high amount of EPE block copolymer provoked a significantly decrease in Young's modulus and simultaneously higher elongation at break.

This behavior was attributed to the plasticization effect provoked by EPE block copolymer. Thus, the modification of CTA with EPE block copolymer decreases Young's modulus value as well as that of tensile strength leading to more elastic materials.

To evaluate the polarity of investigated materials static water contact angle (CTA) measurements were performed to determine the change in the hydrophobicity of the EPE/CTA composites compared to unmodified CTA. Water contact angle images of CTA and EPE/CTA composites are shown in Fig. 4.

The CTA film presented a contact angle value of $70 \pm 0.5^{\circ}$ (Fig. 4a). For 10EPE/CTA composite, Fig. $4 \mathrm{~b}$, the contact angle significantly decreased to $62 \pm 2.0^{\circ}$, suggesting that the EPE/CTA composites were more hydrophilic than CTA. In the case of 40EPE/CTA film (Fig. 4c) the contact angle decreased to $20 \pm 2.5^{\circ}$. Obtained results indicated that the addition of EPE block copolymer had a significant effect on the water resistance of EPE/CTA composites. The pronounced increase in wettability is attributed to the hydrophilic nature of the PEO block (Larrañaga, Mondagon, \& Riccardi, 2007) of the EPE block copolymer.

In addition to the contact angle measurements, water vapor permeability (WVP) was also determined to evaluate hydrophilic or hydrophobic nature of the composites. Table 3 shows WVP values for CTA and investigated EPE/CTA composite films. In this case, the addition of low amount of EPE block copolymer to CTA matrix pro- 
Table 2

Tensile strength, Young's modulus and elongation at break of CTA and investigated EPE/CTA composites. The values correspond to the mean \pm standard deviation.

\begin{tabular}{|c|c|c|c|}
\hline Samples & Tensile strength (MPa) & Youngís Modulus (MPa) & Elongation at break (\%) \\
\hline CTA & $68.31 \pm 1.52$ & $3104.20 \pm 101.93$ & $4.02 \pm 0.85$ \\
\hline 10ЕРЕ/90СТА & $59.50 \pm 1.71$ & $2719.25 \pm 74.00$ & $3.86 \pm 0.13$ \\
\hline 40EPE/60CTA & $9.67 \pm 0.23$ & $633.48 \pm 15.80$ & $17.88 \pm 0.87$ \\
\hline
\end{tabular}

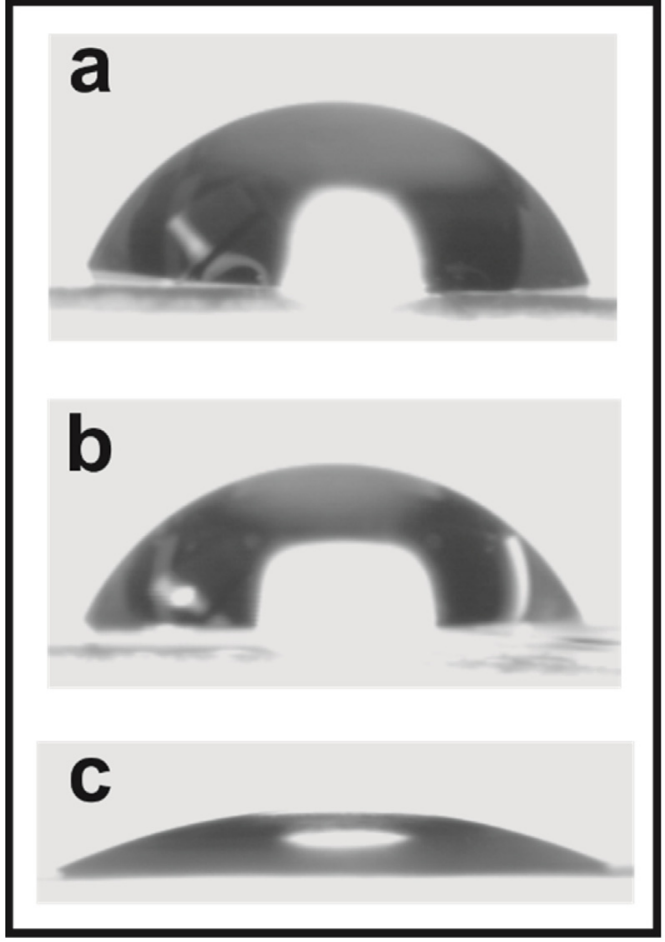

Fig. 4. Water contact angle images of a) CTA, b) $10 \mathrm{EPE} / \mathrm{CTA}$ and c) $40 \mathrm{EPE} / \mathrm{CTA}$.

Table 3

Water vapor permeability values of CTA and investigated EPE/CTA composites.

\begin{tabular}{lll}
\hline Samples & WVTR $\left(\mathrm{g} \mathrm{h}^{-1} \mathrm{~m}^{-2}\right)$ & WVP $\left(\times 10^{-12} \mathrm{~g} \mathrm{~m}^{-1} \mathrm{~s}^{-1} \mathrm{~Pa}^{-1}\right)$ \\
\hline CTA & $20.63 \pm 0.78$ & $1.55 \pm 0.03$ \\
10EPE/90CTA & $18.83 \pm 1.02$ & $1.40 \pm 0.10$ \\
40EPE/60CTA & $29.24 \pm 3.27$ & $2.17 \pm 0.13$ \\
\hline
\end{tabular}

vokes a slight reduction of WVP value. On contrary, 40EPE/60CTA composite showed significant increase in permeability, being $40 \%$ higher if compared to CTA. These results can be attributed to the hydrophilic character of PEO block of the EPE block copolymer. Higher amount of EPE block copolymer involves higher content of hydrophilic PEO block resulting in a considerable increase in water permeability value.

Fig. 5 shows cytotoxicity assay of CTA and investigated EPE/CTA composites performed with human osteogenic cells (MG63) (Alakhova et al., 2010; Reahead et al., 2015; Ruggiero et al., 2015). Obtained results demonstrated that there was no significant statistical difference $(p \geq 0.05)$ between the cell viability of CTA and investigated EPE/CTA composite films regardless of EPE amount. Consequently, in this preliminary assay fabricated EPE/CTA composite films were non-toxic. Nevertheless, further research is needed to be able to determine their therapeutic effectiveness.

\section{Conclusions}

This research work presented a suitable approach to develop transparent sustainable multiphase nanostructured compos-

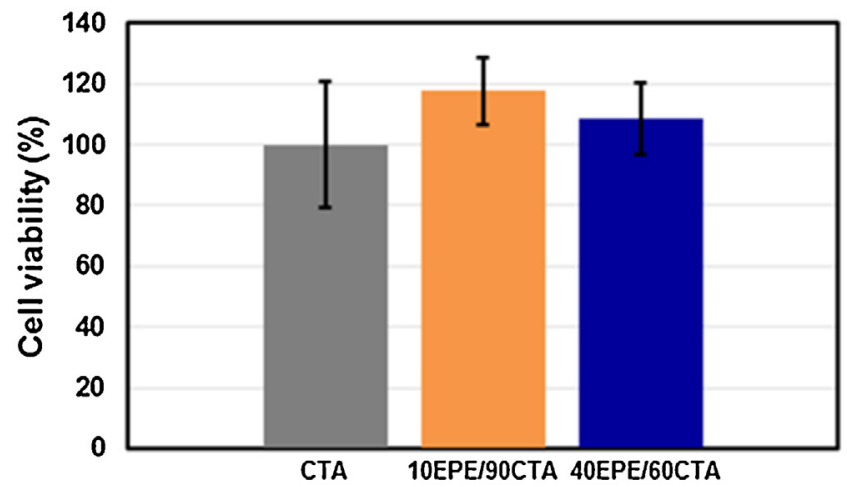

Fig. 5. MTT-formazan viability/cytotoxicity assay of CTA and investigated EPE/CTA composites performed with human osteogenic cells (MG63). One-way ANOVA: $\mathrm{p}=0.435$.

ites based on cellulose triacetate (CTA) as matrix and using poly(ethylene oxide)-b-poly(propylene oxide)-b-poly(ethylene oxide) (EPE) triblock copolymer as templating agent. The selfassembly capability of EPE block copolymer allow us to fabricate transparent films with tunable nanostructures playing with the ratio of EPE block copolymer. Based on mechanical characterization of investigated composites, it can be concluded that the addition of EPE block copolymer resulted in a significant decrease in Young's modulus value as well as that of tensile strength leading to more elastic materials. Moreover, the wettability and water vapor permeability were considerably improved by blending with EPE block copolymer due to the hydrophilic nature of PEO block. The results concerning the cytotoxicity showed that the cell viability of CTA film was not affected by the blending with EPE block copolymer regardless of the amount of EPE block copolymer.

Presented research work will open up new prospect for the development of sustainable nanostructured composites that could be used as platform to dispersion and selective location of different nanofillers which give them potential applications in the field of tissue engineering.

\section{Acknowledgements}

Financial support from Spanish Ministry of Economy and Competitiveness and European Community in the frame of MAT2015-66149-P projects and from the Basque Government for Grupos Consolidados project (IT776-13) are gratefully acknowledged. This work was also supported by Brazilian agencies CNPq, FAPESP, and CAPES. Moreover, we are grateful to the 'Macrobehavior-Mesostructure-Nanotechnology' SGIker unit of the UPV/EHU.

\section{Appendix A. Supplementary data}

Supplementary data associated with this article can be found, in the online version, at http://dx.doi.org/10.1016/j.carbpol.2017.02. 070 . 


\section{References}

Alakhova, D. Y., Rapport, N. Y., Batrakova, E. V., Timoshin, A. A., Li, S., \& Nicholls, D. (2010). Differential metabolic response to pluronic in mdrand non-MDR cells: A novel pathway for chemosensitization of drug resistant cancers. Journal of Controlled Release, 142, 89-100.

Ali, S. F. A. (2014). Biodegradation properties of poly- $\varepsilon$-caprolactone, starch and cellulose acetate butyrate composites. Journal of Polymers and the Environment, 22, 359-364.

Belgacem, M. N., \& Gandini, A. (2008). Monomers, polymers and composites from renewable resources. Elsevier Ltd.

Braganca, F. C., \& Rosa, D. S. (2003). Thermal, mechanical and morphological analysis of poly((-caprolactone), cellulose acetate and their blends. Polymers for Advanced Technologies, 14, 669-675.

Brandao, L. R., Yoshida, I. V. P., Felisberti, M. I., \& Gonçalves, M. C. (2013). Preparation and characterization of cellulose acetate/polysiloxane composites Cellulose, 20, 2791-2802.

Builes, D. H., Hernández-Ortiz, J. P., Corcuera, M. A., Mondragon, I., \& Tercjak, A. (2014). Effect of poly(ethylene oxide) homopolymer and two different poly(ethylene oxide-b-poly(propylene oxide)-b-poly(ethylene oxide) triblock copolymers on morphological, optical, and mechanical properties of nanostructured unsaturated polyester. ACS Applied Materials Interfaces, 6, 1073-1081.

Fidale, L. C., Issbrucker, C., Silva, P. L., Lucheti, C. M., Heinze, T., \& El Seoud, O. A. (2010). Probing the dependence of the properties of cellulose acetates and their films on the degree of biopolymer substitution: Use of solvatochromic indicators and thermal analysis. Cellulose, 17, 937-951.

Fischer, S., Thuemmler, K., Volkert, B., Hettrich, K., Schimidt, I., \& Fischer, K. (2008). Properties and applications of cellulose acetate. Macromolecular Symposia, 262, 89-96.

Gopiraman, M., Fujimori, K., Zeeshan, K., Kim, B. S., \& Kim, I. S. (2013). Structural and mechanical properties of cellulose acetate/graphene hybrid nanofibers: Spectroscopic investigations. Express Polymer Letters, 7, 554-563.

Guo, Q., Thomann, R., \& Gronski, W. (2003). Nanostructures, semicrytalline morphology, and nanoscale confinement effect on the crystallization kinetics in self-organized block copolymer/thermoset blends. Macromolecules, 36 , 3635-3645.

Hamley, I. W. (2003). Nanostructure fabrication using block copolymers. Nanotechnology, 14, R39-R54.

Huang, F. Y., Wu, X. J., Yu, Y., \& Lu, Y. H. (2015). Preparation and properties of cellulose laurate $(\mathrm{CL})$ /starch nanocrystals acetate (SNA) bio-nanocomposites. Polymers, 7, 1331-1345.

Jayalakshmi, A., Rajesh, S., Kim, I. C., Senthilkumar, S., Mohan, D., \& Kwon, Y. N. (2014). Poly(isophthalamide) based graft copolymer for the modification of cellulose acetate ultrafiltration membranes and a fouling study by AFM imaging. Journal of Membrane Science, 465, 117-128.

Jeon, G. W., An, J. E., \& Jeong, Y. G. (2012). High performance cellulose acetate propionate composites reinforced with exfoliated graphene. Composites: Part $B, 43,3412-3418$.

Ji, S., Wan, L., Liu, C. C., \& Nealey, P. F. (2016). Directed self-assembly of block copolymers on chemical patterns: A platform for nanofabrication. Progress in Polymer Science, 54-55, 76-127.
Kamal, H., Abd-Elrahim, F. M., \& Lotfy, S. (2014). Characterization and some properties of cellulose acetate-co-polyethylene oxide blends prepared by the use of gamma irradiation. Journal of Radiation Research and Applied Sciences, 7 , $146-153$.

Larrañaga, M., Mondagon, I., \& Riccardi, C. C. (2007). Miscibility and mechanical properties of an amine-cured epoxy resin blended with poly(ethylene oxide). Polymer International, 56, 426-433.

Martínez-Felipe, A., Ballester-Sarrias, E., Imrie, C. T., \& Ribes-Greus, A. (2010). Preparation and thermal characterization of films containing liquid crystals in a cellulose acetate substrate for externally regulated applications. Journal of Applied Polymer Science, 115, 3282-3294.

Morelli, F. C., \& Ruvolo Filho, A. (2010). Nanocompósitos de polipropileno e argila organofílica: difração de raio $\mathrm{x}$, espectroscopia de absorção na região do infravermelho e permeaçãoao vapor d'água. Polimeros-Ciencia E Tecnologia, 20, $121-125$.

Onofrei, M. D., Dobos, A. M., Stoica, I., Olaru, N., Olaru, L., Ioanid, E. G., et al. (2012). Surface properties and biocompatibility of cellulose acetates. Journal Applied Polymer Science, 125, 2521-2528.

Onofrei, M. D., Dobos, A. M., Stoica, I., Olaru, N., Olaru, L., \& Ioan, S. (2014). Lyotropic liquid crystal phases in cellulose acetate phthalate/hydroxypropyl cellulose blends. Journal of Polymers and the Environment, 22, 99-111.

Park, H. M., Misra, M., Drzal, L. T., \& Mohanty, A. K. (2004). Green nanocomposites from cellulose acetate bioplastic and clay: Effect of eco-friendly triethyl citrate plasticizer. Biomacromolecules, 5, 2281-2288.

Paunonen, S. (2013). Strength and barrier enhancements of cellophane and cellulose derivative films: A review. BioResources, 8, 3098-3121.

Reahead, M., Giuseppe, M., Nawaz, S., Carbone, P., Gorecki, D. C., Alexander, C., et al. (2015). Relationship between the affinity of PEO-PPO-PEP block copolymers for biological membranes and their cellular effects. Pharmaceutical Research, 29, 1908-1918.

Ruggiero, R., Carvalho, V. A., Silva, L. G., Magalhães, D., Ferreira, J. A., Menezes, H. H. M., et al. (2015). Study of in Vitro degradation of cellulose acetate membranes modified and incorporated with tetracycline for use as an adjuvant in periodontal reconstitution. Industrial Crops and Products, 72, 2-6.

Shuiping, L., Lianjiang, T., Weili, H., Xiaoqiang, L., \& Yanmo, C. (2010). Cellulose acetate nanofibers with photochromic property: Fabrication and characterization. Materials Letters, 64, 2427-2430.

Singh, A. N., Thakre, R. D., More, J. C., Sharma, P. K., \& Agrawal, Y. K. (2015). Block copolymer nanostructures and their applications: A review. Polymer-Plastics Technology and Engineering, 54, 1077-1095.

Siqueira, G., Bras, J., \& Dufresne, A. (2010). Cellulosic bionanocomposites: A review of properties and applications. Polymers, 2, 728-765.

Smart, T., Lomas, H., Massignani, M., Flores-Merino, M. V., Ruiz Perez, L., \& Battaglia, G. (2008). Block copolymer nanostructures. Nano Today, 3, 38-46.

de Moraes, A. C. M., Andrade, P. F., de Faria, A. F., Simoes, M. B., Salomao, F. C. C. S. Barros, E. B., et al. (2015). Fabrication of transparent and ultraviolet shielding composite films based on graphene oxide and cellulose acetate. Carbohydrate Polymers, 123, 217-227. 